\title{
Characteristics and institutional initiatives that improve the surgical antibiotic prophylaxis use
}

\author{
C Schmitt, RA Lacerda* \\ From 3rd International Conference on Prevention and Infection Control (ICPIC 2015) \\ Geneva, Switzerland. 16-19 June 2015
}

\section{Introduction}

There is little data about adherence to surgical antibiotic prophylaxis guidelines in Brazil.

\section{Objectives}

To recognize the institutional initiatives to improve antibiotic prophylaxis practices in neurosurgery.

\section{Methods}

Cross-sectional observational study, carried out with a population consisting of hospitals, medical records of neurosurgical patients, Infection Control Team (ICT), surgical team. The sample of hospitals and surgical team was used for convenience and the records for each hospital was calculated based on $40 \%$ of overall adherence.

\section{Results}

Among the nine assessed hospitals, five achieved quality certification in 2010. The mean weekly hours of ICT per hospital bed and per critical bed was 0.7 and 3.8. Eight hospitals disclosed SSI rates, seven stratified by surgical specialty, six created the antibiotic prophylaxis guidelines with the surgeons' approval; in four the recommendations were disseminated. Of the 1,011 neurosurgeries 38 were excluded due to lack of records. Overall adherence was $10.0 \%$. The administration route was appropriate in $100 \%$, dose in $90.6 \%$, indication in $90.0 \%$ and time of onset in $77.1 \%$. There was a lower adherence regarding duration (26.1\%) and a statistically significant association between hours of ICT/ICU bed ( $\mathrm{p}=0.048)$, dissemination of surgical antibiotic prophylaxis use guidelines $(\mathrm{p}=0.035)$, adherence monitoring $(\mathrm{p}=0.024)$, disclosing of results $(\mathrm{p}=0.015)$ and the period of the day when the surgery occurred ( $\mathrm{CI}=1.7$ to 6.6). Among the total of 43 anesthesiologists and surgeons interviewed more than $80 \%$ agreed with the

Medical-Surgical, University of São Paulo, São Paulo, Brazil institutional guidelines and more than $50 \%$ reported they always followed them.

\section{Conclusion}

The number of ICT professionals/critical bed, dissemination of guidelines, monitoring and disclosing of results are associated with higher adherence regarding antibiotic prophylaxis use; period of surgery, dose (IC $1.72-6.65$ ) and initial time (IC 1.12 - 3.01) and surgery type, initial time (IC 1.24 - 4.25) and duration (IC 1.09 - 2.59). The ICT had structure as required by law, but had shortcomings regarding the process of guideline implementation, monitoring and dissemination of results.

\section{Disclosure of interest}

None declared.

Published: 16 June 2015

doi:10.1186/2047-2994-4-S1-P81

Cite this article as: Schmitt and Lacerda: Characteristics and institutional initiatives that improve the surgical antibiotic prophylaxis use.

Antimicrobial Resistance and Infection Control 2015 4(Suppl 1):P81.

Submit your next manuscript to BioMed Central and take full advantage of:

- Convenient online submission

- Thorough peer review

- No space constraints or color figure charges

- Immediate publication on acceptance

- Inclusion in PubMed, CAS, Scopus and Google Scholar

- Research which is freely available for redistribution 